\title{
DEMOCRACIA NAS ETECS BASEADA NA LEGISLAÇÃO
}

\author{
DEMOCRACY IN ETECS BASED ON LEGISLATION
}

\author{
Silvânia Soares da Silva Santos ${ }^{1}$ \\ Raquel Gomes Meirelles ${ }^{2}$ \\ Antonio Carlos Muniz Ventura Júnior ${ }^{3}$
}

\begin{abstract}
RESUMO
As discussões sobre o conceito de gestão democrática na escola, o processo de democratização do acesso ao ensino público, a estrutura burocrática na instituição e a participação da comunidade, faz do diretor escolar um administrador e/ou gestor da unidade, pautada em ações burocráticas e técnicas em que são questionadas as condições de administrar a estrutura e a inter-relação com a comunidade, para que o desenvolvimento educacional ocorra com transparência e qualidade nas escolas técnicas estaduais, alimentando o interesse dos alunos na sua capacitação e posicionamento profissional no mercado de trabalho. Assim, a legislação vem de encontro com a democracia nas instituições e questiona a postura do diretor ou legislador educacional na gestão democrática das escolas técnicas estaduais, em função do seu gerenciamento e sua capacidade na formação dos pilares da participação do corpo docente, comunidade e poder público nas demandas do mercado profissionalizante. Analisar a forma de provimento da direção das Escolas Técnicas Estaduais é o objetivo da presente pesquisa. Esse objetivo se desdobrará na discussão em torno de eleição, indicação ou concurso para o provimento do cargo, contextualizando historicamente as formas utilizadas pelo centro para o exercício dessa função/cargo, desde 1980 até 2018, que servirá de pano de fundo para a análise da problemática em torno das questões que envolve o papel do gestor escolar na direção das escolas técnicas estaduais.
\end{abstract}

Palavras-chave: Escola Técnica Estadual. Diretor Escolar. Gestão Escolar.

\begin{abstract}
Discussions about the concept of democratic management at school, the process of democratization of access to public education, the bureaucratic structure in the institution and the participation of the community make the school principal an administrator and / or manager of the unit, based on bureaucratic and techniques in which the conditions of managing the structure and the interrelationship with the community are questioned, so that the educational development occurs with transparency and quality in the state technical schools, feeding the students interest in their qualification and professional positioning in the labor market. . Thus, the legislation meets democracy in the institutions and questions the posture of the educational director or legislator in the democratic management of state

I Profa. Me. da Faculdade de Tecnologia (FATEC) de Sertãozinho - São Paulo - Brasil. E-mail: silvaniasoares.ss@gmail.com

II Profa Esp. da Faculdade de Tecnologia (FATEC) de Sertãozinho-São Paulo - Brasil. E-mail: meirelles.raquel@uol.com.br

III Prof. Esp./mestrando da Faculdade de Tecnologia (FATEC) de Sertãozinho-São Paulo - Brasil. E-mail: acm.ventura@gmail.com
\end{abstract}




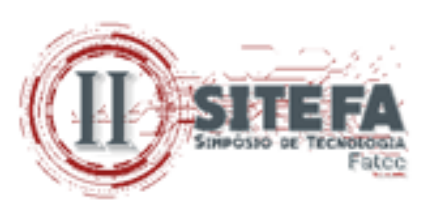

technical schools, due to their management and their ability to form the pillars of faculty, community and power participation. the demands of the professional market. Analyzing how to provide the direction of the State Technical Schools is the objective of this research. This objective will unfold in the discussion around election, nomination or contest to fill the position, historically contextualizing the forms used by the center for the exercise of this function / position, from 1980 to 2018, which will serve as a background for the analysis of the position. problematic around the issues surrounding the role of the school manager in directing state technical schools.

Keywords: State Technical School. School Director. School Management.

Data de submissão do artigo: 23/07/2019.

Data de aprovação do artigo: 10/09/2019.

DOI:

\section{INTRODUÇÃO}

A participação da comunidade na escola, como todo processo democrático, é um caminho que se faz ao caminhar, o que não elimina a necessidade de se refletir previamente a respeito dos obstáculos e potencialidades que a realidade apresenta para a ação, onde a democratização se faz na prática. Não obstante guiada por concepção teórica do real e de suas determinações e potencialidades, a democracia só se efetiva por atos e relações que se dão no nível da realidade concreta.

Sem transformação na prática das pessoas não há sociedade que se transforme de maneira consciente e duradoura. É aí, na prática escolar cotidiana, que precisam ser enfrentados os determinantes mais imediatos do autoritarismo como manifestação, num espaço restrito, dos determinantes estruturais mais amplos da sociedade. "Para examinarmos, mesmo que apenas de passagem, os determinantes imediatos do autoritarismo que, no interior da escola, dificultam a participação efetiva da comunidade na gestão escolar", é preciso mencionar os múltiplos interesses dos grupos que aí interagem, bem como os condicionantes materiais, institucionais e ideológicos desse autoritarismo (PARO, 2016a, p. 26).

A motivação, para a realização desse artigo fundamenta-se na indagação da aplicação da Democracia como princípio da educação nas Escolas Técnicas do Estado de São Paulo (ETEC).

\section{GESTÃO DEMOCRÁTICA}

A gestão democrática nos sistemas públicos de ensino e na própria administração dos serviços públicos vem sendo objeto de reflexões, pois é um dos princípios constitucionais do ensino público na Constituição Federal de 1988 (OLIVEIRA, 2011).

A busca da democratização da gestão educacional tem inspirado "os legisladores a contemplar dispositivos que busquem legitimação sobre assunto, exemplo disso é o inciso VI do artigo 206, da Constituição Federal", ao definir as bases dos princípios em que o ensino será ministrado (SILVA, 2002, p. 41).

Acerca da gestão escolar democrática do ensino público, é de fundamental importância a participação de diferentes segmentos da comunidade escolar e mesmo da comunidade externa, "a maneira de como cada sistema realiza o provimento do cargo de diretor, a 


\section{(II) SIIEFA}

implantação e o funcionamento dos colegiados, a descentralização pedagógica, administrativa e financeira, e a autonomia escolar na qual o projeto político pedagógico é apontado" (SALVETTI, 2011, p. 26).

Aceitando que a gestão democrática deve implicar necessariamente a participação da comunidade, falta ainda uma maior precisão do conceito de participação nas decisões. Isto não elimina, obviamente, a participação na execução; "mas também não a tem como fim e sim como meio, quando necessário, para a participação propriamente dita, que é a partilha do poder, a participação na tomada de decisões" (PARO, 2016b, p.22).

Ao analisar quais são as condições de gestão democráticas e as práticas do ambiente escolar há a possibilidade de entender a influência da falta de gestão democrática na formulação e implementação de políticas educacionais no Brasil que são representadas por sujeitos envolvidos no ambiente escolar, agindo politicamente "[...] pelo viés da democracia ou do autoritarismo por relação de experiências no poder" (CIENA, 2016, p.172).

A Lei de Diretrizes e Bases da Educação Nacional, LDB - Lei n ${ }^{\circ}$ 9.394/96 faz referência direta a essa forma de gestão em pelo menos três vezes, no inciso VIII do artigo $3^{\circ}$, no artigo 14 e no artigo 56. A partir do que estabeleceu a Constituição Federal e a LDB, com referência à Gestão Democrática, "surgiram dispositivos como gestão colegiada, descentralização administrativa, autonomia das escolas e Eleição de Diretores em leis dos nossos sistemas estaduais e municipais de educação" (SILVA, 2002, p. 42).

A gestão democrática como princípio da educação nacional, segundo a LDB, "é presença obrigatória em instituições escolares, a forma não violenta que faz com que a comunidade educacional se capacite para levar a termo um projeto pedagógico de qualidade" para os cidadãos ativos com a participação dos profissionais da educação (OLIVEIRA, 2011, p.17).

Segundo Brito (2013), "a comunidade é formada por todas as pessoas envolvidas em um espaço organizacional abrangendo todos os níveis de hierarquia e o espaço interno e externo", concebido aqui, como o público alvo estratégico para o qual a gestão deve direcionar suas metas e objetivos, representada na Figura 1.

\section{Figura 1- Comunidade Escolar}

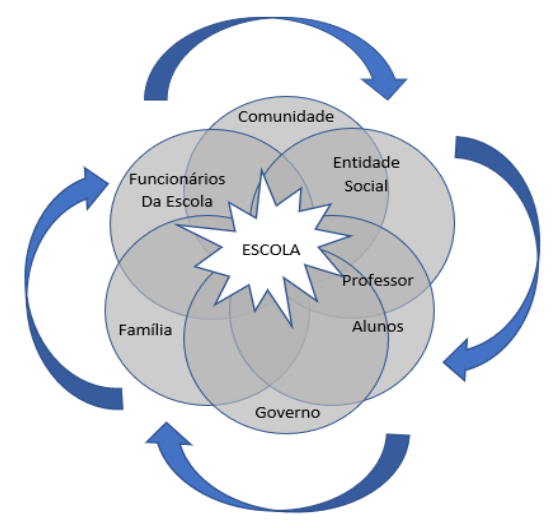

Fonte: Brito (2013)

Um modelo bem planejado de gestão participativa e bem implementado se constitua um elemento capaz de possibilitar a aproximação da comunidade local da escola (BRITO, 2013). 


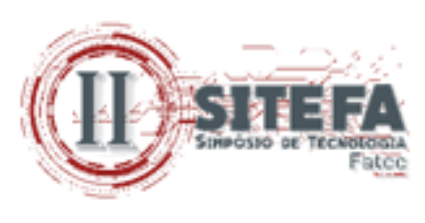

Para tal, a organização possui interfaces por meio das quais interage com todo o meio, e que por sua vez é composto por todas as pessoas envolvidas no espaço organizacional, criando uma sinergia entre Escola-Estado-Comunidade.

Por isso, a garantia de um artigo constitucional que estabelece a gestão democrática não é suficiente para sua efetivação. A leitura se faz dos termos gestão e democracia e, ainda mais, da combinação de ambos, varia conforme os projetos em disputa (SILVA, 2006).

Antunes (2012, p.6-7) considera que, “[...] se faz necessário que em uma sociedade democrática, as instituições que a compõem se desenvolvam de forma também democrática e participativa", como princípio da educação nacional estabelecido na atual legislação, conduzida pelo diretor, enquanto gestor da educação na escola, precisa ter como norte de sua ação as políticas públicas estabelecidas na amplitude do Estado, a partir da construção coletiva dos projetos político-pedagógicos.

\subsection{Gestão Democrática na Escola}

Paro (2016b, p.15) determina que, "se queremos uma escola transformadora, precisamos transformar a escola que temos".

E continua,

É nesse sentido, portanto, que vejo a necessidade de a escola organizar-se democraticamente com vistas a objetivos transformadores. E aqui subjaz, portanto, o suposto de que a escola só poderá desempenhar um papel transformador se estiver junto com os interessados, se se organizar para atender aos interesses das camadas às quais essa transformação favorece[..] (PARO, 2016b, p.17).

Atualmente, os cidadãos querem saber dos processos de decisão por meio da transparência dos atos do governo e exercer a fiscalização do exercício do poder, fazendo com que a comunidade educacional se capacite para levar a termo um projeto pedagógico de qualidade (OLIVEIRA, 2011).

A democratização da gestão escolar supõe a participação da comunidade em suas decisões, podendo ocorrer por órgãos colegiados ou instituições auxiliares de ensino. A participação da comunidade não deve ficar restrita apenas aos processos administrativos, mas nos processos pedagógicos que supõe o envolvimento da comunidade nas questões relacionadas ao ensino (SILVA, 2006).

Logo, a gestão do projeto pedagógico é tarefa coletiva do corpo docente e se volta para a obtenção de um outro princípio constitucional da educação nacional que é a garantia do padrão de qualidade, posto no inciso VII do art. 206 (OLIVEIRA, 2011).

Dentro de um modelo de gestão educacional participativa, a escola é planejada para se transformar em um centro comunitário permanente, integrando escola-família-comunidade, compartilhada por pais, alunos e professores compartilhando os serviços oferecidos pela escola, constituindo elementos motivadores para a colaboração na construção e implantação do projeto político-pedagógico, tornando um fator chave de sucesso (SANTOS, 2003; MURILLO et al. 2007 apud BRITO, 2013, p.85-86).

Para Ferreira (2000 apud SILVA, 2006, p. 31) essa forma de gestão

[...] embora ainda não tenha sido incorporada à prática social global e à prática educacional brasileira e do mundo, é um valor mundialmente consagrado como forma de cidadania, sociedade justa e igualitária e fonte de humanização. 


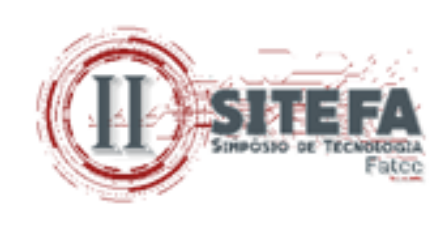

Portanto, ainda que se pudesse esperar uma maior explicitação desse novo princípio constitucional de uma Lei de Diretrizes e Bases da Educação Nacional e a extensão do mesmo para todo o sistema de ensino em sua abrangência total, "uma lei ou uma norma só será sustentável se ela estiver alinhada na consciência e na prática dos educadores" (OLIVEIRA, 2011, p. 20).

Nesse sentido, a comunidade adquire condição dupla de exercer a cidadania de forma plena, não só garante o espaço legítimo para fazer parte, como usufrui desse espaço enquanto instrumento de poder que representa. Cabe às associações docentes dos sistemas de ensino ampliar a consciência relevância desse princípio, proporcionando a gestão democrática que faça avançar a educação escolar como instituição republicana aberta à representatividade e à participação (BRITO, 2013, p. 24).

\subsection{Gestão Democrática e Legislação}

A gestão democrática, numa escola, tem como principal objetivo promover a transparência e participação de toda comunidade escolar em sua gestão. Assim compete ao Gestor Escolar a motivação de todos no compromisso pela qualidade da educação.

Entende-se que o trabalho educacional, por sua natureza, demanda um esforço compartilhado, realizado a partir da participação coletiva e integrada dos membros de todos os segmentos das unidades de trabalho envolvidos (LÜCK, 2017).

É de competência dos Estados, municípios e instituições de ensino a definição de suas normativas sobre a gestão democrática. A LDB, em seu artigo 14, dispõe que os sistemas de ensino federal, estadual e municipal definirão as normas da gestão democrática em suas instâncias, respeitando os princípios de "[...] participação dos profissionais da educação na elaboração do projeto pedagógico da escola"; e "[...] participação das comunidades escolar e local em conselhos escolares ou equivalentes" (BRASIL, 1996).

De acordo com o artigo 205 da Constituição Federal (BRASIL, 1988), “[...] a educação é direito de todos e dever do Estado e da família", a fim de proporcionar aos cidadãos "[...] o pleno desenvolvimento, seu preparo para o exercício da cidadania e sua qualificação para o trabalho". Ainda segundo o artigo 205, a educação “[...] será promovida e incentivada com a colaboração da sociedade" (BRASIL, 1988).

A Constituição Federal de 1988 aponta para as ações necessárias na gestão educacional, com vistas a imprimir-lhe qualidade ao caráter democrático, cooperativo, planejado e responsável da gestão educacional, orientado pelos princípios em seu artigo 206:

O ensino será ministrado com base nos seguintes princípios: [...] VI - gestão democrática do ensino público, na forma da lei; [...] (BRASIL, 1988).

A participação dos segmentos da comunidade escolar é amparada pela Lei de Diretrizes e Bases da Educação Nacional (LDB) - Lei no 9.394, de 20 de dezembro de 1996, que apresenta uma breve orientação com relação a prática da gestão participativa, para a promoção da gestão democrática no ambiente escolar, em seu artigo 14:

Os sistemas de ensino definirão as normas da gestão democrática do ensino público na educação básica, de acordo com as suas peculiaridades e conforme os seguintes princípios: I - participação dos profissionais da educação na elaboração do projeto pedagógico da escola; II - participação das comunidades escolar e local em conselhos escolares ou equivalentes (BRRASIL, 1996 apud SILVA, 2002, p.42). 


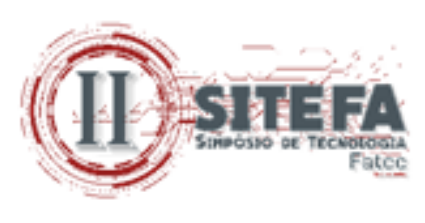

Aqui estabelece que a comunidade escolar e extraescolar na gestão da escola são os princípios que deveriam ser os propulsores do processo da constituição de uma gestão mais democrática das escolas, observado, naturalmente, no âmbito de suas autonomias. Os sujeitos escolares são representados pelo Conselho de Escola, que geralmente é composto por membros da comunidade escolar, constituída basicamente por alunos, professores, servidores e pais.

Segundo Silva (2002, p. 43), “[...] a democratização dos processos pedagógicos implica na participação da comunidade nas questões relacionadas ao ensino, na definição do conteúdo programático dos componentes curriculares e as estratégias pedagógicas".

A comunidade escolar definirá as normas da gestão democrática do ensino público na participação das comunidades escolar e local em conselhos escolares ou equivalentes.

Na gestão democrática da escola já está necessariamente implícita a participação da população em tal processo (PARO, 2016b).

A democratização da gestão escolar é de fundamental importância o envolvimento da comunidade, proporcionando experiências participativas aos mecanismos institucionais ao provimento de cargos e ao papel do gestor.

A nível estadual, as Normas Regulamentais Básicas da Secretaria de Estado da Educação, da gestão democrática, capítulo I, artigo $7^{\circ}$ refere-se que:

[...] a gestão democrática tem por finalidade possibilitar à escola maior grau de autonomia, de forma a garantir o pluralismo de ideias e de concepções pedagógicas, assegurando padrão adequado de qualidade do ensino ministrado (SÃO PAULO, 1998, p. 113).

Remetendo-nos ainda à $\mathrm{CF} / 88$, que é a fonte de todos nossos direitos e obrigações, e também à LDB/96, que normatiza a prática educacional, em seu Artigo 12, Incisos I a VII, determina as principais delegações que se referem à gestão escolar, no que diz respeito as suas respectivas unidades de ensino:

\footnotetext{
Art. 12 - Os estabelecimentos de ensino, respeitadas as normas comuns e as do seu sistema de ensino, terão a incumbência de:

I - elaborar e executar sua proposta pedagógica;

II - administrar seu pessoal e seus recursos materiais e financeiros;

III - assegurar o cumprimento dos dias letivos e horas-aula estabelecidas;

IV - velar pelo cumprimento do plano de trabalho de cada docente;

$\mathrm{V}$ - prover meios para a recuperação dos alunos de menor rendimento;

VI -articular-se com as famílias e a comunidade, criando processos de integração da sociedade com a escola;

VII - informar os pais e responsáveis sobre a frequência e o rendimento dos alunos, bem como sobre a execução de sua proposta pedagógica (BRASIL, 1996).
}

Nestes sete incisos descritos acima, observar-se a dimensão da gestão escolar com a competência da administração escolar para a gestão democrática e participativa com responsabilidades compartilhadas com a comunidade interna e externa, ou seja: funcionários, docentes, alunos, pais, representantes da comunidade, dentre outros. Este artigo deixa claro também, em seus incisos, as responsabilidades, poderes e autonomia administrativa e orçamentária para o Gestor Escolar, direcionando para solução dos desafios da qualidade da educação no âmbito da instituição, conforme prevê o artigo 15 da LDB: 


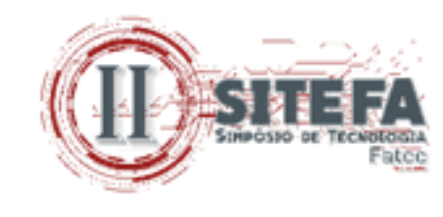

Art. 15. Os sistemas de ensino assegurarão às unidades escolares públicas de educação básica que os integram progressivos graus de autonomia pedagógica e administrativa e de gestão financeira, observadas as normas gerais de direito financeiro público (BRASIL, 1996).

No âmbito estadual, o capítulo I, artigo $8^{\circ}$ compactua com a LDB:

[...] que o processo de construção da gestão democrática na escola será fortalecido por meio de medidas e ações dos órgãos centrais e locais responsáveis pela administração e supervisão da rede estadual de ensino, mantidos os princípios de coerência, equidade e co-responsabilidade da comunidade escolar na organização e prestação dos serviços educacionais (SÃO PAULO, 1998).

Segundo Lück (2002, p.11), a gestão escolar tem como objetivo final proporcionar a aprendizagem efetiva e significativa ao aluno, desenvolvendo nele as habilidades que demanda a sociedade, dentre os quais se destacam:

[...] pensar criativamente, analisar informações e proposições diversas, de forma contextualizada, expressar ideias com clareza, oralmente e por escrito; empregar a aritmética e a estatística para resolver problemas; ser capaz de tomar decisões fundamentadas e resolver conflitos.

Nesta nova percepção de organização, educadores, professores e diretores se encontram diante de uma série de novos desafios em função dos impactos da chamada gestão democrática da escola (SICCA, 2015).

Porém, o projeto da escola não é responsabilidade apenas da sua direção, pelo contrário, o projeto pedagógico é marcado pela diversidade para todas as escolas de um sistema educacional, proporcionando autonomia e suporte a gestão democrática ao seu projeto político-democrático (GADOTTI, 2012).

\subsection{Gestão Democrática na Legislação das Etecs}

O Conselho Deliberativo é órgão máximo do Centro Paula Souza (CPS), responsável por exercer a jurisdição superior na instituição de ensino com a função de aprovar, elaborar, propor ou determinar medidas para garantir e aprimorar a política educacional do CPS.

\footnotetext{
Artigo $1^{\circ}$ - O Conselho Deliberativo do CEETEPS é órgão normativo e deliberativo incumbido da jurisdição superior do Centro e tem como finalidade apreciar, decidir e regulamentar assuntos de sua competência. Parágrafo Único - A decisão do Conselho denominar-se-á Deliberação, quando versar sobre matéria normativa (CPS,2013).
}

O Conselho Deliberativo também é o órgão responsável pela aprovação do Regimento Comum das Etecs que instituem as normativas para a gestão escolar, inclusive os procedimentos para a provisão do Diretor Escolar da Unidade.

Abaixo do Conselho Deliberativo está o Diretor Superintendente, que deve ser integrante da carreira docente do CPS e nomeado pelo Governador, tem a função de coordenar, supervisionar e dirigir todas as atividades do CEETEPS, segundo o artigo 11 do Decreto $n^{\circ} 58.385$, de 13 de setembro de 2012. 


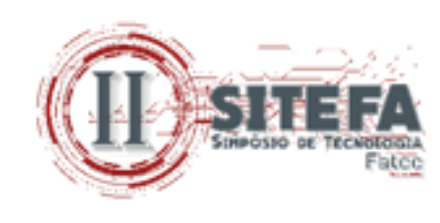

\begin{abstract}
Artigo 11 - Os empregos públicos em confiança de Diretor Superintendente e ViceDiretor Superintendente são privativos dos integrantes das carreiras docentes do CEETEPS e serão nomeados pelo Governador, com base em listas tríplices, uma para cada função, propostas pelo Reitor da UNESP, ouvido o Conselho Deliberativo do CEETEPS (SÂO PAULO, 2012).
\end{abstract}

E ainda em seu artigo 12, descreve que compete à Superintendência assegurar a execução das diretrizes do Conselho Deliberativo e dos planos, programas e projetos adotados Já sobre a organização Administrativa das Etecs, há como órgão maior o Conselho de Escola, órgão máximo na unidade de ensino, acima da Direção Escolar, citado no Capítulo 1 da CEETEPS descrito abaixo.

CAPÍTULO I - Do Conselho de Escola. Artigo 10 - A Etec terá, como órgão deliberativo, o Conselho de Escola, integrado por representantes da comunidade escolar e da comunidade extraescolar (CEETEPS, 2013).

Assim, o Regimento Comum das Etecs incorpora o princípio da gestão democrática previsto pela $\mathrm{CF} / 88$, tornando-se o principal instrumento legal regulador das ações das unidades de ensino, bem como norteador da gestão da Etec, conforme artigo $3^{\circ}$ da Deliberação CEETEPS Nº 003, de 18-7-2013: “[...]valorizando as relações baseadas no diálogo e no consenso, tendo como práticas a participação, a discussão coletiva e a autonomia" (CEETEPS, 2013).

Ainda determina, em parágrafo único, que a:

[...] participação deverá possibilitar a todos os membros da comunidade escolar o comprometimento no processo de tomada de decisões para a organização e para o funcionamento da Etec e propiciar um clima de trabalho favorável a uma maior aproximação entre todos os segmentos das Etecs (CEETEPS, 2013).

Sendo assim, a gestão democrática como princípio da educação, é a forma por meio da qual, a comunidade educacional se capacita para levar um projeto pedagógico de qualidade e possa gerar cidadãos ativos compromissados com a sociedade (CURY, 2002, p.17).

A gestão da escola ainda conta com contribuição das instituições auxiliares:

[...] que tenham como objetivo colaborar no aprimoramento do processo educacional, na assistência ao aluno e aos demais membros da comunidade escolar e na integração família-escola-comunidade (CEETEPS 2013).

O CEETEPS (2013) considera instituições auxiliares o Grêmio Estudantil, o Conselho de Escola, a APM e a Cooperativa Escola nas Etecs, com o objetivo de contribuir com o aprimoramento da comunicação e da consolidação das relações interpessoais com as instituições auxiliares da escola, tais como o Grêmio Estudantil, o Conselho de Escola, a Associação de Pais e Mestres e a Cooperativa Escola, nas Etecs.

É tão importante para o CEETEPS articulação das instituições auxiliares nas Etecs, visando contribuir para a sua gestão, que em 2016 foi criada uma "Comissão de Gestão Participativa nas Etecs" pela Portaria da Diretora Superintendente, publicada em 19/08/2016.

Isto torna a gestão escolar transparente, com qualidade e expõe ao público e a todos algo que pode ser diretamente assistido por qualquer um, proporcionando de natureza pública, 


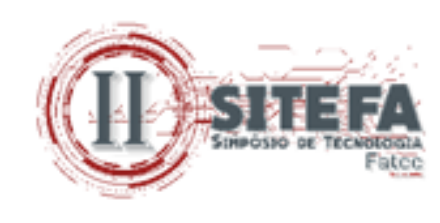

conhecimento de uma realidade em uma reunião ou de uma decisão que interessa a todos (CURY, 2002).

Com isso, a participação das camadas populares da sociedade nos conselhos escolares, é de tal importância, que enriquece o instrumento da democracia na gestão da escola pública, fragilizando a guerra de movimento na luta contra a hegemonia capitalista (ROMÃO apud GADOTTI, 2012).

É necessário considerar que na prática os discursos tendem ao autoritarismo e o liberalismo mal consegue escamoteá-lo, principalmente nos postos de direção, porque são liberais com alunos, professores, funcionários ou pais (PARO, 2016c).

Para tal, o modelo democrático não é único capaz de tornar exitosa a ação educativa da escola. Por isso, é preciso incentivar a experimentação pedagógica e, sobretudo, ter uma mentalidade aberta ao novo, pois a educação para todos supõe todos pela educação, em função de pequenas ações que são essenciais à grande mudança (GADOTTI, 2012).

\section{PROCEDIMENTOS METODOLÓGICOS}

Como procedimento metodológico, realizou-se a pesquisa documental. A análise documental favorece a observação do processo de maturação ou de evolução de indivíduos, grupos, conceitos, conhecimentos, comportamentos, mentalidades, práticas, entre outros (CELLARD, 2008).

A pesquisa será documental baseado na LDB $n^{\circ}$ 9394/96, em seus princípios estabelecidos para a gestão democrática nas escolas, como também na Constituição Federal de 1988, e nas normativas do CEETEPS que resultaram em suas Deliberações, Editais, Portarias e Ofícios, especialmente no Regimento Comum das Etecs, Deliberação $\mathrm{n}^{\mathbf{0}}$ 003, de 18/07/2013, Deliberação CEETEPS 01 de 11/01/2000, e literaturas produzida sobre o conceito de gestão democrática. Sendo assim, são constituídas em etapas onde a primeira etapa é composta por um processo de qualificação dos candidatos através de análise de currículo; prova escrita e por uma entrevista. Na segunda etapa, os candidatos aprovados, podem se inscrever para participar do processo eleitoral da (s) escola (s) em que têm interesse; a escolha ocorrerá através da votação dos professores, funcionários e alunos. A terceira etapa é a designação do Diretor pelo Superintendente, com base nos três candidatos mais votados pelo colégio eleitoral (CEETEPS, 2013). A participação da comunidade no processo de eleição do diretor escolar, traz envolvimento e compromisso, gerando reflexão e sentimento de cidadania, tornando-a responsável pela escolha do candidato eleito, configurando uma gestão democrática, uma vez que existe a participação da comunidade na decisão e na organização escolar.

Comparando a quantidade de eleitores dos quadros de eleição de 2012 com o de eleição de 2016 percebemos um crescimento na adesão dos votantes, demonstrando uma maior participação e adesão ao processo eleitoral da ETEC pela comunidade. Em 2012 tivemos um quadro de participantes num total de 1309 para 1734, que comparado à população total, representou $53,49 \%$ para $62,69 \%$ respectivamente, demonstrando um crescimento percentual em quase $10 \%$.

Mesmo não tendo a informação da população total de votantes em 2008, a quantidade dos eleitores é expressiva em relação aos anos seguintes, uma vez que não ocorreu diminuição na polução dos votantes (informação obtida em internamente).

Embora a legislação do CPS considere pesos diferentes para os seguimentos de alunos, professores e funcionários, 20, 60 e 20 sucessivamente, e considerando o objetivo, análise da 


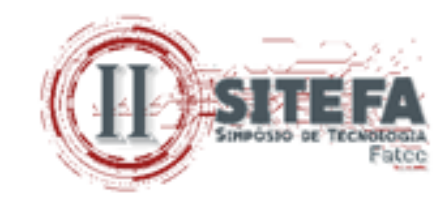

participação, independente de peso, não podemos deixar de notar, que o seguimento com maior peso que são os professores, tiveram participação menor em relação à outros seguimentos, em 2012 e 2016 possuem participação percentuais de 67\% e 83\% sucessivamente contra o seguimento de funcionários que foi de $90 \%$ e $85 \%$ sucessivamente, maiores que grupo anterior, mesmo com diminuição de participação no último processo eleitoral.

Já o segmento dos alunos demonstra crescimento de uma eleição para outra. Em 2012 tiveram participação de 52\% e em 2016 de $61 \%$, demonstrando um crescimento de $9 \%$, que foi a maior contribuição no crescimento de eleitores em 2016.

\section{RESULTADOS E DISCUSSÃO}

As políticas educacionais do Brasil, em geral, possuem princípios que denotam uma grande atenção com a gestão democrática que orienta a educação nacional, presentes em todos os instrumentos legais nas três esferas de governo (federal, estadual e municipal), bem como apresenta-se existente também no Regimento Comum das Etecs.

Uma vez que as leis do governo federal e estadual regem a circunvizinhança do princípio da gestão democrática, de forma genérica e forçosa, torna às escolas imprescindíveis na execução do funcionamento das ações de gestão democrática, saindo da formalidade e culminado em sua execução.

É por isso que para o atingimento do objetivo da gestão democrática nas Etecs, entre em cena o seu regimento, privilegiando a atuação efetiva da comunidade, representada por seus órgãos colegiados para uma Gestão Escolar participativa.

O Regimento comum das ETECs é bem claro em seus objetivos, destacando a gestão escolar como princípio, desta forma alinhada às legislações nacionais de educação, evidenciando que para ocorrer uma gestão democrática é necessário a participação de toda a comunidade, representada individualmente ou por órgãos colegiados representativos. $\mathrm{O}$ artigo 102, faz parte do Capítulo, dos Direitos do Corpo Discente, ressaltando assim o direito de todos se fazerem presentes no processo da democracia.

\section{CONCLUSÃO}

Pode-se perceber que a Constituição Federal promulgada em 1988, bem como a Lei de Diretrizes e Bases da Educação Nacional de 1996 (Lei no. 9.394/96), representaram um avanço na educação brasileira ao estabelecerem a gestão democrática para as escolas públicas.

Dentro do contexto da legislação nacional, está a legislação das ETECs, contemplando também em sua administração a gestão democrática, previstas em seu Regimento Comum, publicado na Deliberação CEETEPS $n^{\circ}$ 003, de 18/07/2013, seu artigo $3^{\circ}$ destaca a participação da comunidade para um de trabalho favorável entre todos os segmentos das Etec, garantindo que o trabalho coletivo seja de fundamental importância para o adequado desempenho da Etec, em que, cada membro da comunidade escolar é corresponsável pelas definições tomadas pelo grupo.

Porém, para que a ocorra a democracia nas Etecs não é bastante sua previsão em normas legais, tampouco seu destaque no discurso escolhido por educadores, ou seja, é fundamental o comprometimento da comunidade interna e externa, existência de órgãos colegiados e instituições auxiliares com efetivos representantes da comunidade escolar e com 


\section{(110)}

autonomia para decidir questões de interesse coletivo e cumprimento das normativas estabelecidas, visando sempre o aluno a que tudo mais está submetido.

\section{REFERÊNCIAS}

ANTUNES, José Adilson Santos; Cunha, J. L.. A Organização da escola: o diretor e seu trabalho. Linguagens \& Cidadania, v. 1, p. 1-12, 2012.

BRASIL. Constituição da República Federativa do Brasil. Brasília de 1988. Disponível em: http://www.planalto.gov.br/ccivil_03/constituicao/ConstituicaoCompilado.Htm. Acesso em: 06 out. 2017.

Lei de Diretrizes e Bases da Educação Nacional. Lei n. 9.394, de 20 de dezembro de 1996. Diário Oficial da União, Brasília, 23 dez. 1996. Disponível em: http://www.planalto.gov.br/ccivil_03/LEIS/L9394.htm. Acesso em: 02 nov. 2018

BRITO, R. O. Gestão e Comunidade Escolar: ferramentas para a Construção de Uma Escola Diferente do Comum. Brasília: Liber Livro, 2013. 160p.

CEETEPS. Deliberação Ceeteps $n^{\circ}$ 003, de 18 de julho de 2013. Regimento Comum das Etecs do CPS. Regimento Comum Etec. São Paulo, SP: Imprensa Oficial do Estado de São Paulo, 18 jul. 2013. Disponível em: http://www.portal.cps.sp.gov.br/etec/regimentocomum/regimento-comum-2013.pdf. Acesso em: 02 nov. 2018.

Deliberação $\mathbf{n}^{0}$ 1, de 11 de janeiro de 2000. Fixa Normas complementares ao Processo de Qualificação e Eleição dos Diretores das Etecs do CEETEPS. Processo Qualificação Diretor Etec. São Paulo, SP, 11 jan. 2000. Disponível em: http://www.cpscetec.com.br/cpscetec/arquivos/deliberacao_eleicao.pdf. Acesso em: 02 abr. 2018.

CELLARD, A. A análise documental - a pesquisa qualitativa: enfoques epistemológicos e metodológicos. Petrópolis: Petrópolis Vozes, 2008. 316 p.

CENTRO PAULA SOUZA (CEETEPS). Deliberação CEETEPS nº 003, de 18-07-2013. Aprova o Regimento Comum das Escolas Técnicas Estaduais do Centro Estadual de Educação Tecnológica Paula Souza. São Paulo: CEETEPS, 2013. Disponível em: http://www.portal.cps.sp.gov.br/etec/regimento-comum/regimento-comum-2013.pdf. Acesso em: 02 abr. 2018.

CIENA, Fabiana Polican. A gestão pública das políticas educacionais para a efetivação democrática do direito à educação no Brasil: da democracia cognitiva à democracia participativa. 2016. 303f. Tese (Doutorado) - Faculdade de Direito, Universidade de São Paulo. São Paulo, 2016. Disponível em:

file:///C:/Users/Usuario/Downloads/Tese_Fabiana_Polican_Ciena.pdf. Acesso em: 02 abr. 2018. 
CURY, Carlos Roberto Jamil. Gestão Democrática da Educação: Exigências e Desafios. 2002. Disponível em: http://www.seer.ufrgs.br/rbpae/article/viewFile/25486/14810. Acesso em: 18 mai. 2018.

GADOTTI, M.; ROMÃO, J. E. Autonomia da escola: princípios e propostas. 7. ed. São Paulo: Cortez, 2012. 199 p.

LUCK, H. A Escola Participativa: o trabalho do gestor escolar. Rio de Janeiro: DP\&A, 2002. 2017. 116 p.

H. Gestão Educacional: Uma Questão Paradigmática. 12. ed. Petrópolis: Vozes,

OLIVEIRA, Maria Auxiliadora Monteiro. Gestão Educacional: novos olhares, novas abordagens. 8 ed. Petrópolis, RJ: Vozes, 2011. 119p.

PARO, V. H. Crítica da Estrutura da Escola. 2. ed. São Paulo: Editora Cortez, 2016a. 254 p.

V. H. Gestão Democrática da Escola Pública. 4. ed. São Paulo: Cortez, 2016b. 141

p.

V. H. Por dentro da Escola Pública. 4. ed. São Paulo: Cortez, 2016c. 400 p.

SALVETTI, T.A.S. A qualidade do ensino na dimensão da gestão escolar democrática: um estudo de caso na EMEB Alfredo Naime a partir do INDIQUE. 2011. 98f. Dissertação (Mestrado) - Faculdade de Economia, Administração e Contabilidade de Ribeirão Preto, Universidade de São Paulo, Ribeirão Preto, São Paulo, 2011. Disponível em: http://www.teses.usp.br/teses/disponiveis/96/96132/tde-03012012155416/publico/ThalesASSalvetti_Corrigida.PDF. Acesso em: 18 mai. 2018.

SÃO PAULO (Estado). Decreto $\mathbf{n}^{\mathbf{0}} \mathbf{5 8 3 8 5}$, de 13 de setembro de 2012. Aprova o Regimento do Centro Estadual de Educação Tecnológica 'Paula Souza" - CEETEPS. São Paulo, SP, 14 set. 2012. Disponível em: https://www.al.sp.gov.br/norma/168149. Acesso em: 27 out. 2018.

Parecer CEE n⿳ 67/98 - CEF/CEM - Aprovado em 18-03-98. Disponível em: http://siau.edunet.sp.gov.br/ItemLise/arquivos/notas/parcee67_98.htm. Acesso em: 10 set. 2019

SICCA, N. A. L.. Diálogos na educação básica: políticas, currículo e discurso. $1^{\text {a }}$ Edição. Curitiba, PR: CRV, 2015.

SILVA, Nilson Robson Guedes. Reeleição: continuidade ou continuísmo? (Um estudo com base na reeleição dos diretores das Escolas Técnicas do CEETEPS/NRSE-Campinas).

Dissertação (Mestrado). Campinas, SP: [s.n.], 2002. 
Nilson Robson Guedes. A participação da comunidade escolar como fator de influência na reeleição/não reeleição dos diretores de escola. (Um estudo realizado nas Escolas Técnicas do Centro Paula Souza). Dissertação (Doutorado). Campinas, SP: [s.n.], 2006. 